\title{
Performance pay and adverse selection
}

\author{
Espen R. Moen*and Åsa Rosen ${ }^{\dagger}$
}

December 18, 2001

\begin{abstract}
We study equilibrium wage contracts in a labour market with adverse selection and moral hazard. Firms offer incentive contracts to their employees to motivate them to exert effort. Providing incentives comes, however, at a cost, as it leads to misallocation of effort across tasks. With ex ante identical workers, the optimal wage contract is linear, and the equilibrium resource allocation optimal. With ex ante heterogenous workers, firms may increase the incentive power of the wage contract to attract the better workers. The resulting equilibrium is separating, in the sense that workers self-select on contracts. Furthermore, the contracts offered to the good workers are too high powered compared to the contracts that maximise welfare.
\end{abstract}

\section{Introduction}

In his book on personnel economics, Lazear (1998) stresses the importance of performance pay for firm profitability. Lazear argues that the gains from performance pay are twofold. First, and most obviously, it helps solving a moral hazard problem, as it provides incentives for workers to work harder. Second, high-powered performance contracts affect the quality of workers applying to the firm. When workers have private information about their productivity at the hiring stage, firms can attract higher quality workers by offering more

*Address: Norwegian School of Management (BI), Box 580 N-1301 Sandvika, Norway E-mail: espen.moen@bi.no

$\dagger$ Address: Swedish Institute for Social Research, Stockholm University, S106-91 Stockholm, Sweden. E-mail: asa.rosen@sofi.su.se 
high-powered contracts. That is, good workers self-select into jobs offering more performance sensitive compensations, e.g., large bonus packages. Indeed, Lazear (2000) documents that the productivity improvement following the introduction of performance contracts can be attributed in approximately equal parts to the effort and selection effects. More generally, advocates of performance pay stress the selection effect when advocating incentive pay (The Economist, (1998)).

It is, however, not obvious whether the private gains associated with the selection effect also reflect a social gain, as the number of talented people in the economy is limited. Furthermore, there may be costs associated with performance pay (agency costs). This paper examines to what extent a rat-race between firms for talented workers may lead to excessive use of performance pay and thus an inefficient allocation of resources. Our central proposition is that the incentive power of the equilibrium wage contract exceeds its socially efficient level. To this end we analyse a simple adverse selection model of the Rotchild and Stiglitz (1976) type. The contribution of this paper is to analyse the welfare properties of markets with heterogenous workers in which firms offer workers incentive contracts, as so often recommended by personnel economists.

The costs of introducing performance pay can broadly be divided into three categories:

1. Suboptimal risk sharing. If firms are risk neutral and workers are risk averse, an optimal allocation of risk implies that the firm carry all the risk and thus fully insures the workers. With performance pay, the worker is exposed to uncertainty, and has to be compensated for this through a higher wage. The firm thus faces a trade-off between incentives and insurance to the employee. (See e.g. Hart and Holmstrom (1987)).

2. Rent extraction. If a worker have private information about his own productivity, he may exploit this and obtain an information rent. The stronger is the incentive scheme, the higher is the rent. The firm thus faces a trade-off between incentives and rents. This trade-off is thoroughly analysed in the theory of regulation (see e.g. Laffont and Tirole (1993)), but is also relevant for employment contracts (Moen and Rosen (2001)). 
3. Misallocation of effort. This is relevant if not all aspects of a worker's output can be adequately measured and compensated for. In this case, the worker will concentrate too much on tasks that give rise to performance pay while neglecting the tasks that do not. Standard examples include too much focus on quantity relative to quality when output is measured in terms of quantity, or neglection of cooperation when an individual's own production only forms a basis for his bonus (see e.g., Holmstrom and Milgrom (1991))

In this paper, we focus on agency costs created by misallocation of effort, though we could equally well have chosen agency costs associated with suboptimal risk sharing or with rent extraction.

\section{Model and Benchmark}

\subsection{Framework}

We consider a one-shot model with many firms and many employees in each firm. All agents are risk neutral. Each worker undertakes two tasks. The total value of production from any given worker is given by

$$
y=e_{1}+e_{2}+\varepsilon
$$

where $e_{1}$ and $e_{2}$ is his effort on task one and two, respectively. We may think of $e_{1}$ as effort related to collaboration and $e_{2}$ as effort related to performing individual tasks. The term $\varepsilon$ may be given several interpretation. It may reflect how difficult or profitable the particular task in question is, it may reflect a worker-firm specific productivity component, or it may simply be measurement error. Below we interpret $\varepsilon$ as a task-specific component, reflecting the difficulty of performing the particular task in question. What is important at this point is the information structure regarding $\varepsilon$, which by assumption is as follows:

1. While firms do not observe the realisation of $\varepsilon$ they know its distribution which is continuous. To simplify the notation, $\varepsilon$ is symmetric on the interval $[-\bar{\varepsilon}, \bar{\varepsilon}]$, where $\bar{\varepsilon}$ may be infinite.

2. The worker observes $\varepsilon$ after the contract is signed, but before he determines his effort level. 
The existence of $\varepsilon$ implies that a simple, non-linear contracts in which a bonus is given if output is above a certain threshold are not efficient, as will be made clear below. The firm can neither directly observe $e_{1}$ nor $e_{2}$, nor $y$ but only a distorted measure $\widetilde{y}$ of their output, given by

$$
\begin{aligned}
\widetilde{y} & =(1-\gamma) e_{1}+(1+\gamma) e_{2}+\varepsilon \\
& =\widetilde{e}+\varepsilon
\end{aligned}
$$

where $\gamma>0$ reflects the measurement error. The firm thus observes a distorted measure of $e_{1}$ and $e_{2}$. Due to measurement problems, collaboration will be weighted down relative to individual performance when bonuses are calculated.

Effort above a certain level is costly for workers, and this cost depends on the type of the worker, which is either high (h) or low (l). The effort cost of a worker of type $k$ is

$$
C_{k}\left(e_{1}, e_{2}\right)=\frac{\left(e_{1}-e^{0 k}\right)^{2}}{2}+\frac{\left(e_{2}-e^{0 k}\right)^{2}}{2}
$$

for $e_{1}, e_{2} \geq e^{0 k}, k=l, h$. We assume that $e^{0 l}<e^{0 h}$, reflecting that the latter type is more productive.

The sequence of the moves is as follows:

1. The firm signs contracts (individually) with all its employees. The contracts are binding for both sides.

2. The noise terms are revealed to the workers (different values for different workers) but not to the firms. As the contract is binding, the worker cannot quit if a low value of $\varepsilon$ realizes.

3. Each worker chooses effort levels $e_{1}$ and $e_{2}$

4. The firm observes $\widetilde{y}=\widetilde{e}+\varepsilon$ for each worker and renumerates them accordingly. 


\subsection{Optimal contracts with observable types}

We first consider the optimal contract with observable worker types. As $\widetilde{y}$ is the only variable the firm observes, the contract can be made contingent on $\widetilde{y}$ only.

Among all effort combinations that give the worker the same wage $w$, he always chooses the pair $\left(e_{1}, e_{2}\right)$ that minimises his effort costs. The Lagrangian associated with this minimisation problem is

$$
L=\left(e_{1}-e^{0}\right)^{2} / 2+\left(e_{2}-e^{0}\right)^{2} / 2-\lambda\left[e_{1}(1-\gamma)+e_{2}(1+\gamma)-\widetilde{e}\right]
$$

It follows that

$$
\frac{e_{2}-e^{0}}{e_{1}-e^{0}}=\frac{1+\gamma}{1-\gamma}
$$

independently of $\widetilde{e}$ and of the chosen wage contract.

The value to the firm of the worker's effort is $e=e_{1}+e_{2}$. Given that the agents' choose effort according to (1), it follows that

$$
e_{1}+e_{2}=2 e^{0} \frac{\gamma^{2}}{1+\gamma^{2}}+\frac{1}{1+\gamma^{2}} \widetilde{e}
$$

The value to the firm of a higher $\widetilde{e}$ (higher observed effort) is highest when $\gamma=0$, i.e., when there are no distortions. Note that the value of observed effort decreases proportionally with $1+\gamma^{2}$. Thus, if $\gamma=1$, in which case only individual effort is observed, the value of observed effort is twice as high (for a given $e$ ) as the corresponding costs with no measurement distortions.

An optimal wage contract $f(\widetilde{y})$ maximises the firm's expected profit given the following constraints:

1. Incentive compatibility constraint: Workers choose effort levels so as to maximise their utility

2. Individual rationality: the contract provides each worker with at least his reservation expected utility denoted by $u^{0}$.

The firm can manipulate a worker's choice of $\widetilde{e}$, but not how the worker allocate total effort among the two tasks. The value to the firm of observable effort is given by equation (2). At the margin, the value of observable effort is constant and equal to $\frac{1}{1+\gamma^{2}}$. Consider a linear wage contract $w=\alpha+\beta \widetilde{y}$, 
and choose $\beta=\frac{1}{1+\gamma^{2}}$. For any realisation of $\varepsilon$, this contract gives the worker the right incentives: on the margin, the worker (who carries the effort cost) is paid the entire marginal gain from his effort, given by $\frac{1}{1+\gamma^{2}}$. As the firm can extract all the rent by adjusting $\alpha$ in such a way that the participation constraint binds, this linear contract is optimal.

Due to the task-specific component $\varepsilon$, the firm cannot implement the optimal effort level by a trigger wage contract in which the wage is discontinuous at the optimal effort level. Denote the optimal level of the observable effort by $e^{*}$. In order to implement the optimal effort level for all values of $\varepsilon$, the wage contract must be such that the marginal effect of increased $\widetilde{y}$ on wages must be equal to $\frac{1}{1+\gamma^{2}}$ on an interval $\left[e^{*}-\bar{\varepsilon}, e^{*}+\bar{\varepsilon}\right]$. Thus, any optimal contract is linear with slope $\frac{1}{1+\gamma^{2}}$ on this interval.

Proposition 1 The unique optimal contract is linear (on the relevant intervals) and can be written as

$$
w=\alpha+\beta \widetilde{y}
$$

where $\beta=\frac{1}{1+\gamma^{2}}$ and $\alpha=u^{0}-\frac{2 e^{0}+1}{1+\gamma^{2}}$

The optimal value of $\alpha$ is derived in the appendix. Finally, with free entry of firms, firms must earn zero profit in equilibrium. A firm's expected profit is given by

$$
\begin{aligned}
E \pi & =e_{1}+e_{2}-\alpha-\beta \widetilde{e} \\
& =2 e^{0} \frac{\gamma^{2}}{1+\gamma^{2}}+\frac{1}{1+\gamma^{2}} \widetilde{e}-\alpha-\frac{1}{1+\gamma^{2}} \widetilde{e} \\
& =2 e^{0} \frac{\gamma^{2}}{1+\gamma^{2}}-\alpha \\
& =0
\end{aligned}
$$

It thus follows that

$$
\alpha=2 e^{0} \frac{\gamma^{2}}{1+\gamma^{2}}
$$

and that $u^{0}=2 e^{0}+\frac{1}{1+\gamma^{2}}$. 


\section{Two types of workers}

We now consider the case with two types of workers. As explained above, we capture the differences in productivity by assuming that $e^{0}$ may take two values, $e^{0 h}$ or $e^{0 l}$, with $e^{0 h}>e^{0 l}$. If the worker's type were observable, workers of different types would be offered different contracts. The incentive power of the contract would be the same for both types, $\beta^{h}=\beta^{l}=\frac{1}{1+\gamma^{2}}$. It follows, however, from equation (3) that $\alpha^{h}>\alpha^{l}$ in the full information case.

Here we assume that a worker's type is private information, and cannot be observed by the firms. The firm may induce self-selection by the workers, just as in insurance markets with adverse selection (Rothchild and Stiglitz (1976)). We assume that each firm is offering at most one contract (this is not important, as there is constant returns to scale in each firm). An equilibrium in this market must satisfy the following conditions:

1. Workers apply for firms that offer them the best contract

2. Firms choose contracts so as to maximise their profit, given the worker's behaviour

\section{Free entry of firms}

We look at a competitive equilibrium with market clearing, and (at least for now) do not allow for rationing as a sorting mechanism. In this section we only consider linear contracts, as we know that the linear contract is optimal with one worker type only. We will then move on and look at non-linear contracts.

The first thing to note is that the equilibrium with observable types is not an equilibrium when the type is private information. Since the only difference between the contracts given to the good and the bad workers is that the constant term is higher in the former, low-type workers have an incentive to apply for the jobs assigned to the high-type workers

As in Rotchild and Stiglitz (1976), there does not exist any pooling equilibrium either. The point is that if all (or a continuum of) firms offer a contract that attracts both worker types, then a firm that deviates slightly, by offering a contract with stronger incentives and lower fixed pay, may end up with high-type workers only. The reason is that as good workers produce more than a bad worker, they are more willing to accept a lower fixed 
salary component in return for stronger incentives (higher production related bonuses). Thus, by increasing $\beta$ slightly above $\beta^{*}$, and lowering $\alpha$ so that low-type workers are marginally better off with the initial contract, it follows that high-type workers but not low-type workers will be attracted to this firm.

Lemma 1: Suppose the firms in the market offer a pooling contract $\left(\alpha^{*}, \beta^{*}\right)$. Then there exists another contract, arbitrarily close to $\left(\alpha^{*}, \beta^{*}\right)$ (using an Euklidian metric) that attracts high-type workers only.

Proof. Let $u^{0 h}$ and $u^{0 l}$ be the expected income to high-type workers and low-type workers, respectively, in the pooling equilibrium. Let $\delta>0$ be arbitrarily small. We want to show that for any $\delta$ there exists a $k$ such that the contract $\left(\alpha^{*}-k \delta, \beta^{*}+\delta\right)$ attracts high-type workers only, i.e., such that $u^{h}\left(\alpha^{*}-k \delta, \beta^{*}+\delta\right) \geq u^{0 h}$ and $u^{l}\left(\alpha^{*}-k \delta, \beta^{*}+\delta\right)<u^{0 l}$. From the envelope theorem it follows that $\frac{\partial u^{k}}{\partial \beta}=\widetilde{e}^{k}, k=l, h$. From equation (13) in the appendix, we know that for any given contract, $\widetilde{e}^{h}=\widetilde{e}^{l}+2\left(e^{0 h}-e^{0 l}\right)$, and thus that $\frac{\partial u^{h}}{\partial \beta}=\frac{\partial u^{l}}{\partial \beta}+2\left(e^{0 h}-e^{0 l}\right)$. Thus, by increasing $\beta$ by $\delta$ and reducing $\alpha$ with $\widetilde{e}^{h} \delta$ it follows that high-type workers are equally well of with the new contract while low-type workers are strictly worse off by applying for the deviating firm.

The next step is to show that for a given contract, firms prefer to attract high-type workers. In the appendix we show that

$$
\frac{\partial E \pi}{\delta e^{0}}=2(1-\beta)
$$

Thus, as long as $\beta<1$, firms strictly prefer to hire high-type workers rather than low-type workers on a given contract. But this rules out any pooling contracts in which $\beta<1$. Furthermore, a pooling equilibrium with $\beta=1$ does not exist either, as low-type workers would then prefer a contract with $\beta=\frac{1}{1+\gamma^{2}}$ and $\alpha$ set according to proposition 1 .

\section{Proposition 2 There exists no pooling equilibrium}

Thus, any equilibrium of the model has to be a separating equilibrium. Denote the equilibrium wage contracts by $\left(\alpha^{k}, \beta^{k}\right)$, with $k=l, h$. In a separating equilibrium, the contract offered to low-type workers is the one 
described in the previous section with only one type of workers only. If not, a firm that offers such a contract, with a slightly lower $\alpha$ would attract workers and thus make a profit. It follows that $\beta^{l}=\frac{1}{1+\gamma^{2}}$ and $\alpha^{l}=2 e^{0 l} \frac{\gamma^{2}}{1+\gamma^{2}}$.

The contracts for high-type workers must be such that the incentive compatibility constraint for low-type workers binds, ensuring that the latter do not apply for the jobs assigned to high-type workers. At the same time, the zero profit condition for high-type firms must be satisfied.

From the low-type workers' perspective, increasing $\beta^{h}$ reduces the attractiveness of applying for a high-type job for two reasons. First, it reduces the value of the constant term $\alpha$, as more of the wages are paid out as bonuses. Second, it reduces overall productivity in the firm, and due to free entry of firms this ultimately reduces wages. In the appendix, we show that the expected income of a low-type worker applying for a low-type job is given by

$$
E u^{l}\left(\alpha^{l}, \beta^{l}\right)=2 e^{0 l}+\frac{1}{1+\gamma^{2}}
$$

The expected income of this worker when applying for a firm that offers a contract $\left(\alpha^{h}, \beta^{h}\right)$ is given by (from equation 14) in appendix)

$$
E u^{l}\left(\alpha^{h}, \beta^{h}\right)=\alpha^{h}+\beta^{h} 2 e^{0 l}+\beta^{h 2}\left(1+\gamma^{2}\right)
$$

Finally, in a separating equilibrium only high-type workers apply for high type jobs. In the appendix, we show that the zero-profit condition for firms implies the following relationship between $\alpha^{h}$ and $\beta^{h}$ (from equation (20))

$$
\alpha^{h}=2\left(1-\beta^{h}\right) e^{0 h}+2 \beta^{h}\left(1-\beta^{h}\left(1+\gamma^{2}\right)\right)
$$

By combining (14) and (5), it follows that a low-type worker who deviates and applies for a high-type firm obtains utility $E u^{l h}$ given by

$$
\begin{aligned}
E u^{l h} & =2\left(1-\beta^{h}\right) e^{0 h}+2 \beta^{h}\left(1-\beta^{h}\left(1+\gamma^{2}\right)\right)+\beta^{h} 2 e^{0 l}+\beta^{h 2}\left(1+\gamma^{2}\right) \\
& =2 e^{0 l}+2\left(1-\beta^{h}\right)\left(e^{0 h}-e^{0 l}\right)+\left[2 \beta^{h}-\beta^{h 2}\left(1+\gamma^{2}\right)\right] .
\end{aligned}
$$

Before we continue, let us compare this expression with the expression for $E u^{l}$ given by equation (4). The first term is the same in both equations. The second term in (6) reflects the additional income of a low-type worker when applying to a high-type firm, due to the fact that the constant term reflects 
the average productivity of high-type workers, rather than that of low-type workers. When $\beta^{h}=1$, this advantage vanishes. Due to the distorted measure of observable effort, there are, however, costs associated with giving so strong incentives. The last term in (6) is maximised for $\beta^{h}=\frac{1}{1+\gamma^{2}}$, in which case it takes the value of $\frac{1}{1+\gamma^{2}}$, as is the last term of (4). For $\beta^{h}>\frac{1}{1+\gamma^{2}}$, the term decreases in $\beta^{h}$ reflecting that it is costly to increase the incentives above the optimal level. Due to free entry of firms, this cost is ultimately borne by the workers.

In a separating equilibrium, we must have that $E u^{l l} \geq u^{l h}$. In the appendix, we show that this implies that $\beta^{h}$ must satisfy the following inequality (equivalent to equation (26) in the appendix):

$$
\left(\beta^{h}-\frac{1}{1+\gamma^{2}}\right)^{2}\left(1+\gamma^{2}\right) \geq 2\left(1-\beta^{h}\right)\left(e^{0 h}-e^{0 l}\right)
$$

In a separating equilibrium, the incentive compatibility constraint binds. It follows that $\beta^{h}$ lies in the interval $\left(\frac{1}{1+\gamma^{2}}, 1\right)$. If we solve this equation, we find that $\beta^{h}$ is given by (with $\Gamma=\frac{1}{1+\gamma^{2}}$ and $\Delta=e^{h 0}-e^{l 0}$ )

$$
\beta^{h}=\sqrt{\Gamma^{2}\left[(1-\Delta)^{2}-1\right]+2 \Delta \Gamma}+\Gamma(1-\Delta)
$$

We know from Rotchild and Stiglitz (1976) that in an environment where agents with private information self-select a separating equilibrium may not exist, as there may exist a profitable pooling contract that makes both worker types better off. This no-existence result also applies our context, as is illustrated in the figure below.

The figure is set in the $\alpha, \beta$ space. The iso-profit curves $\pi^{h}=0$ and $\pi^{l}=0$ show combinations of $\alpha$ and $\beta$ that yield zero profit given that a firm attracts either high- or low-type workers. In addition, an indifference curve of low-type workers and two indifference curves of high-type workers are drawn. If the worker type were observable, the equilibrium contract would be given by point $\mathrm{A}$ for low-type workers and point $\mathrm{D}$ for high-type workers. With unobservable types, a separating equilibrium must be such that low-type workers prefer to apply for low-type rather than high-type firms. Hence, points A and B are the separating equilibrium candidates. We have also drawn the curve $\pi^{h l}=0$, showing the zero profit line for a firm that 


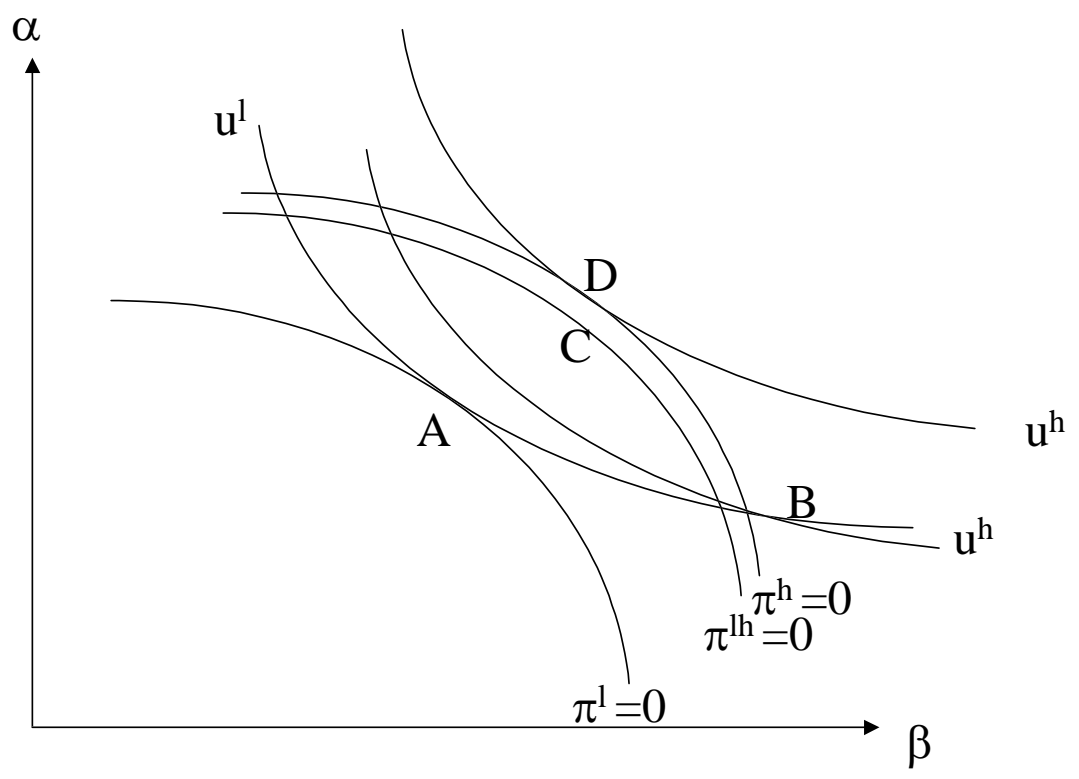

Figure 1:

randomly selects between high-type and low-type workers. We have drawn this curve relatively close to the $\pi^{h}=0$ curve, reflecting a large proportion of high-type workers in the economy. A firm that offers a pooling contract at $\mathrm{C}$ attracts both types of workers and makes a profit. Thus, with parameter constellations as in the figure there does not exist any equilibrium.

In the following, we assume that a separating equilibrium does exist. This can be rationalised in several ways, by imposing restrictions on the parameter set or by refining the equilibrium concept. In a reactive equilibrium (Riley 1979) an equilibrium candidate is broken by a contract only if this contract is strictly profitable and does not become unprofitable once other firms add still more contracts to the menu (Kreps 1990). It can be shown that a reactive equilibrium must be separating.

With unobservable types contracts are distorted relative to the full information contract in order to obtain separation, and this leads to a welfare loss. In what follows, we define welfare as the sum of the agents' individual utility, $W=a u^{l}+(1-a) u^{h}$, where $a$ is the share of low-type workers in this economy. We now consider a planner, faced with the same information constraint as the agents in the market. The planner chooses contracts for 
both high-and low type workers so as to maximise welfare.

It is straight-forward to show that the allocation with one worker type is (constrained) efficient, as it maximises welfare given the information constraints (mainly that observed productivity depends on a distorted measure of effort). With two worker types, it follows that the equilibrium is constraint efficient if the planner can observe the workers' type. When types are unobservable, the planner can obtain the same allocation of resources and thus the same welfare as when the types are observable by offering a pooling contract with $\beta=\frac{1}{1+\gamma^{2}}$ and $\alpha$ set in accordance with the zero profit criterion in a pooling equilibrium. As high-type workers are better off when worker type is observable, while low-type workers are equally well off in equilibrium, it follows that welfare is higher in the equilibrium with observable types than in the separating equilibrium.

Proposition 3 The separating equilibrium is not efficient, as the high-type workers are offered contracts that are too incentive powered ( $\beta^{h}$ is too high)

The overall output in the separating equilibrium exceeds both the output in the welfare optimising equilibrium and the output in the separating equilibrium with observable types. From a welfare point of view this additional output comes at an effort cost that more than outweights the increased output. Compared with the equilibrium with observable worker types, the high-type workers suffer: In order to obtain separation, high-type workers are offered contracts that provides them with too strong incentives. They obtain high salaries, but exert excessive effort and this reduces their overall utility.

One may ask whether the pooling equilibrium Pareto dominates the separating equilibrium. It is possible to show that this holds when the share of low-type workers in the economy is low, i.e. when the separating equilibrium (without refinements) breaks down. 


\section{Extensions}

In this section we briefly discuss extensions that hopefully appear in a future version of the paper.

\section{General contracts}

In the previous section we have only considered linear contracts and have shown that an optimal contract has to be linear in the relevant intervals. If one allows for general contracts, this will therefore not necessarily solve the problem of self selection discussed above.

When non-linear contracts are admitted, a firm may offer a contract which gives zero (or negative) wages if output is below a certain threshold. To avoid distortions for the high-type workers, such a threshold must satisfy the condition $\widetilde{y}^{t} \leq \widetilde{e}^{h}\left(\frac{1}{1+\gamma^{2}}\right)+\varepsilon^{\min }$, where $\varepsilon^{\min }$ is the minimum of the support of $\varepsilon$. Now consider a firm that offers a contract $\left(\alpha^{h}, \frac{1}{1+\gamma^{2}}\right)$, where $\alpha^{h}$ satisfies the zero-profit constraint with high-type workers. In addition, the firm sets a wage $w^{\prime}$ if output is less than $\widetilde{y}^{t}$. Even if there is no lower bound on $w^{\prime}$, we may not be able to obtain separation with this contract, because a low-type worker can always obtain $\widetilde{y}^{t}$ by working sufficiently hard. In addition, there may exist a lower bound on wages the firm can offer because of minimum wages or because workers cannot be forced to stay and therefore have to get a wage that at least covers the effort cost.

A firm that attracts high-type workers chooses a wage contract $f(\widetilde{y})$ that solves the problem

$$
\max \int\left[\tilde{e}^{h}(\varepsilon)+\varepsilon-f\left(\widetilde{e}^{h}(\varepsilon)+\varepsilon\right)\right] d G(\varepsilon)
$$

subject to the following constraints

$$
\begin{aligned}
\widetilde{e}^{h}(\varepsilon) & =\arg \max _{\widetilde{e}} f(\widetilde{e}+\varepsilon)-C\left(\widetilde{e}-e^{0 h}\right) \\
u^{h} & \leq \int\left[f\left(\widetilde{e}^{h}(\varepsilon)+\varepsilon\right)-C\left(\widetilde{e}-e^{0 h}\right)\right] d G(\varepsilon) \\
u^{l} & \geq \int\left[\max _{\widetilde{e}} f(\widetilde{e}+\varepsilon)-C\left(\widetilde{e}-e^{0 l}\right)\right] d G(\varepsilon)
\end{aligned}
$$

Although the welfare loss will be smaller than when we restrict attention to linear contracts, there will still be a welfare loss whenever a linear wage contract does not apply. 


\section{Marginal taxes}

Implementing a single wage contract for all workers in the economy is quite radical, and will create distortions along other dimensions outside the present model. Other less radical policy measures may, however, improve welfare. One such policy measure is taxes on wages above a certain level.

Introducing a marginal tax on high incomes has two effects, both going in the same direction. First, it makes it less tempting for a low-type worker to apply to a high-type firm, as some of the extra income is taxed away. Thus, separation may be obtained with a lower value of $\beta^{h}$. Second, a marginal tax reduces effort for a given $\beta^{h}$, thereby reducing the inefficiencies related to excessive effort. This rises two interesting questions that we will address in the future:

a) If the tax income are doled out in a lump-sum fashion, could taxes as described above be welfare improving?

b) With nonlinear wage contracts: Can it be possible to obtain first best through taxes?

\section{Endogeneous production technology}

Suppose firms can choose between different kinds of technologies, which differs according to for instance the degree of measurement error $\gamma$. Will the firm make the correct technology choices?

4. More radical results with a different cost structure.

In the present model, aggregate output increases although welfare decreases in the separating equilibrium. If we introduce a cost-of-effort function in which the marginal costs of the two tasks are interrelated, this may change. Suppose for instance that a third element is introduced in the cost function, and write it as

$$
C\left(e_{1}, e_{2}\right)=\frac{\left(e_{1}-e^{0}\right)^{2}}{2}+\frac{\left(e_{2}-e^{0}\right)^{2}}{2}+a\left(e_{1}+e_{2}-3 e^{0}\right)^{2}
$$

In this case, the costs of increasing $\beta$ above its optimal level may increase, as this may squeeze out $e_{1}$, and thereby reduce output. 


\section{Appendix}

\subsection{Effort provision and cost minimisation}

First order conditions for the worker's allocation of effort $e_{1}$ and $e_{2}$ :

From the definition of $\widetilde{e}$, it follows that

$$
\left(e_{1}-e^{0}\right)(1-\gamma)+\left(e_{2}-e^{0}\right)(1+\gamma)=\widetilde{e}-2 e^{0}
$$

Substituting out $e_{2}-e_{0}$ by using (1) gives

$$
\left(e_{1}-e^{0}\right)\left[1-\gamma+\frac{(1+\gamma)^{2}}{1-\gamma}\right]=\widetilde{e}-2 e^{0}
$$

or

$$
e_{1}-e^{0}=\frac{\left(\widetilde{e}-2 e^{0}\right)}{2} \frac{1-\gamma}{1+\gamma^{2}}
$$

It thus follows that

$$
e_{2}-e^{0}=\frac{\left(\widetilde{e}-2 e^{0}\right)}{2} \frac{1+\gamma}{1+\gamma^{2}}
$$

The value to the firm of observed worker effort $\widetilde{e}$ :

$$
\begin{aligned}
e_{1}+e_{2} & =2 e^{0}+\frac{\left(\widetilde{e}-2 e^{0}\right)}{2}\left[\frac{1-\gamma}{1+\gamma^{2}}+\frac{1+\gamma}{1+\gamma^{2}}\right] \\
& =2 e^{0}+\left(\widetilde{e}-2 e^{0}\right)\left[\frac{1}{1+\gamma^{2}}\right] \\
& =2 e^{0} \frac{\gamma^{2}}{1+\gamma^{2}}+\widetilde{e} \frac{1}{1+\gamma^{2}}
\end{aligned}
$$

The costs (for workers) of providing observable effort: 
Let us denote the cost function by $C(\widetilde{e})$. From (7) and (8), it follows that

$$
\begin{aligned}
C(\widetilde{e})= & {\left[\frac{\widetilde{e}-2 e^{0}}{2} \frac{1-\gamma}{1+\gamma^{2}}\right]^{2} / 2+\left[\frac{\widetilde{e}-2 e^{0}}{2} \frac{1+\gamma}{1+\gamma^{2}}\right]^{2} / 2 } \\
& \frac{\left(\widetilde{e}-2 e^{0}\right)^{2}}{8}\left[\frac{(1-\gamma)^{2}}{\left(1+\gamma^{2}\right)^{2}}+\frac{(1+\gamma)^{2}}{\left(1+\gamma^{2}\right)^{2}}\right] \\
= & \frac{\left(\widetilde{e}-2 e^{0}\right)^{2}}{4} \frac{1}{1+\gamma^{2}}
\end{aligned}
$$

\subsection{Choice of observable effort, indirect utility, and the effect of entry}

Choice of observable effort

We first derive a worker's choice of observable effort $\widetilde{e}$ for an arbitrary contract. The worker then chooses $\widetilde{e}$ so as to maximise

$$
\begin{aligned}
u & =\alpha+\beta \widetilde{e}-C(\widetilde{e})+\varepsilon \\
& =\alpha+\beta \widetilde{e}-\frac{\left(\widetilde{e}-2 e^{0}\right)^{2}}{4} \frac{1}{1+\gamma^{2}}+\varepsilon
\end{aligned}
$$

with the solution

$$
\widetilde{e}=2 e^{0}+2 \beta\left(1+\gamma^{2}\right)
$$

With an optimal contract, this simplifies to $\widetilde{e}=2 e^{0}+2$.

The indirect utility function

We insert the optimal value of $\widetilde{e}$ given by (13) into the maximand (12), and get

$$
\begin{aligned}
E u & =\alpha+\beta\left(2 e^{0}+2 \beta\left(1+\gamma^{2}\right)\right)-\frac{\left[2 \beta\left(1+\gamma^{2}\right)\right]^{2}}{4} \frac{1}{1+\gamma^{2}} \\
& =\alpha+\beta\left(2 e^{0}+2 \beta\left(1+\gamma^{2}\right)\right)-\beta^{2}\left(1+\gamma^{2}\right) \\
& =\alpha+\beta 2 e^{0}+\beta^{2}\left(1+\gamma^{2}\right)
\end{aligned}
$$


For an optimal contract, it follows that $E u$ is given by

$$
E u=\alpha+2 e^{0} \frac{1}{1+\gamma^{2}}+\frac{1}{1+\gamma^{2}}
$$

Reservation utility $u^{0}$ and the value of $\alpha$ :

The firm sets $\alpha$ such that $E u=u^{0}$, the equilibrium value of $E u$. From (14), it therefore follows that the firm sets $\alpha$ such that

$$
\alpha=u^{0}-\beta 2 e^{0}-\beta^{2}\left(1+\gamma^{2}\right)
$$

Given the optimal value of $\beta, \beta=\frac{1}{1+\gamma^{2}}$, we thus have that

$$
\alpha=u^{0}-\frac{2 e^{0}+1}{1+\gamma^{2}}
$$

Free entry and the value of $\alpha$ :

We have now derived the observed effort, given by (13), for any contract. Inserted into the value of observable effort, equation (10) thus gives

$$
e_{1}+e_{2}=2 e^{0}+2 \beta
$$

For any given contract, it follows from (13) and (17) that

$$
\begin{aligned}
E \pi & =e_{1}+e_{2}-\beta \widetilde{e}-\alpha \\
& =2 e^{0}+2 \beta-\beta\left(2 e^{0}+2 \beta\left(1+\gamma^{2}\right)\right)-\alpha \\
& =2(1-\beta) e^{0}+2 \beta\left(1-\beta\left(1+\gamma^{2}\right)\right)-\alpha
\end{aligned}
$$

Thus, for a given contract, the zero profit condition implies that

$$
\alpha=2(1-\beta) e^{0}+2 \beta\left(1-\beta\left(1+\gamma^{2}\right)\right)
$$

For the optimal contract, it follows that

$$
\alpha=2 \gamma^{2} e^{0} \frac{\gamma^{2}}{1+\gamma^{2}}
$$




\section{$5.3 \quad$ Two types of workers}

Profit and worker type

We want to analyse the effect of the worker's type on firm profit for a given wage contract. From (19) it follows that

$$
\frac{\partial E \pi}{\delta e^{0}}=2(1-\beta)
$$

which is strictly greater than zero for $\beta>0$.

Incentive compatibility constraint

In the high-type market, we know that the zero profit condition holds. Let $E u^{k}(\alpha, \beta)$ denote the expected utility to a worker of type $k$ applying to a job that offers a contract $(\alpha, \beta)$. Combining (14) and (20) implies that a high-type worker applying for a high-type contract may expect a utility

$$
\begin{aligned}
E u^{h h} & =2\left(1-\beta^{h}\right) e^{0 h}+2 \beta^{h}\left(1-\beta^{h}\left(1+\gamma^{2}\right)\right)+\beta^{h} 2 e^{0 h}+\beta^{h 2}\left(1+\gamma^{2} \gamma\right. \\
& =2 e^{0 h}+2 \beta^{h}-\beta^{h 2}\left(1+\gamma^{2}\right)
\end{aligned}
$$

which (of course) is maximised for $\beta^{h}=\frac{1}{1+\gamma^{2}}$. The expected utility of a lowtype worker applying for a high-type job is given by (from (14), then replace $\alpha$ with (20)),

$$
\begin{aligned}
E u^{l}\left(\alpha^{h}, \beta^{h}\right)= & \alpha^{h}+\beta^{h} 2 e^{0 l}+\beta^{h 2}\left(1+\gamma^{2}\right) \\
& 2\left(1-\beta^{h}\right) e^{0 h}+2 \beta^{h}\left(1-\beta^{h}\left(1+\gamma^{2}\right)\right)+\beta^{h} 2 e^{0 l}+\beta^{h 2}\left(1+\gamma^{2}\right) \\
= & 2\left(1-\beta^{h}\right) e^{0 h}+\beta^{h} 2 e^{0 l}+2 \beta^{h}-\beta^{h 2}\left(1+\gamma^{2}\right)
\end{aligned}
$$

The expected utility of a low-type worker applying for a low-type job is (the same formula as (23), with $\beta=\frac{1}{1+\gamma^{2}}$ and $e^{0 l}$ instead of $\left.e^{0 h}\right)$.

$$
E u^{l}\left(\alpha^{l}, \beta^{l}\right)=2 e^{0 l}+\frac{1}{1+\gamma^{2}}
$$

In order to obtain separation, we must have that

$$
E u^{l}\left(\alpha^{l}, \beta^{l}\right) \geq E u^{l}\left(\alpha^{h}, \beta^{h}\right)
$$


or

$$
2 e^{0 l}+\frac{1}{1+\gamma^{2}} \geq 2\left(1-\beta^{h}\right) e^{0 h}+\beta^{h} 2 e^{0 l}+2 \beta^{h}-\beta^{h 2}\left(1+\gamma^{2}\right)
$$

or

$$
\frac{1}{1+\gamma^{2}}-\left[2 \beta^{h}-\beta^{h 2}\left(1+\gamma^{2}\right)\right] \geq 2\left(1-\beta^{h}\right)\left(e^{0 h}-e^{0 l}\right)
$$

The left-hand side can be written as $\left(\beta^{h}-\frac{1}{1+\gamma^{2}}\right)^{2}\left(1+\gamma^{2}\right)$, and the inequality reduces to

$$
\left(\beta^{h}-\frac{1}{1+\gamma^{2}}\right)^{2}\left(1+\gamma^{2}\right) \geq 2\left(1-\beta^{h}\right)\left(e^{0 h}-e^{0 l}\right)
$$

It follows that $\beta^{h}$ lies in the interval $\left(\frac{1}{1+\gamma^{2}}, 1\right)$. 


\section{References}

Kreps, D.M. (1990). A Course in Microeconomic Theory. Prentice Hall, New York.

Laffont, J.J. and J. Tirole (1993). A Theory of Incentives in Procurement and Regulation. MIT Press, Cambridge, Massachusetts.

Hart, O. and B. Holmstrom (1987): The Theory of Contracts, In Advances in Economic Theory: Fifth World Congress, Econometric Society Monographs series, no. 12, Camebridge University Press.

Holmstrom, B., and P. Milgrom. (1991). Multitask Principal-Agent Analyses: Incentive Contracts, Asset Ownership, and Job Design, Journal of Law, Economics, and Organizations 7: 24-52.

Moen, E. R., and A. Rosén (2001). Incentive Contracts and Unemplyment, Mimeo.

Riley, J. (1979). "Informational Equilibrium". Econometrica, 47: 331-59

Rotschild, M. and J.E. Stiglitz (1976). "Equilibrium in Competitive Insurance Markets: An Essay on the Economics of Imperfect Information". Quarterly Journal of Economics 17: 557-66.

The Economist (1998). Incentives. Pay survey. 29th of August 